\title{
ANALYTICAL METHODS FOR THE DETERMINATION OF ACEPHATE PESTICIDE RESIDUES IN SOME VEGETABLES
}

\author{
I. E. H. Elgailani* and A. A. A. Alghamdi \\ Department of Chemistry, Faculty of Sciences and Arts at Baljurashi, Albaha University, \\ Albaha, P.O.Box 1988, Saudi Arabia \\ *E-mail : gailani23@hotmail.com
}

\begin{abstract}
The research aimed to estimate the levels of pesticide residues of acephate $75 \%$ SP in some vegetable samples in Albaha local area, Saudi Arabia. Three samples of fresh vegetables were selected and analyzed namely were Coriandrum sativum (leaves), Petroselinum crispum and Eruca sativa which are considered to be the commonly used vegetables. The UV/VIS spectrophotometer was used to estimate the quantity of the pesticide in terms of a reference sample of the pesticide under study. The pesticide residues in the three vegetable samples were identified by using Thin Layer Chromatography (TLC) by using two different developing systems, one is 5\% acetic acid in ethyl acetoacetate and the other is formic acid: acetic acid: methanol 1: 1:5. The results of the study showed the presence of acephate pesticide residues in these selected vegetables with a concentration of $14.25 \mathrm{mg} / \mathrm{kg}$ in Coriandrum sativum (leaves), $8.10 \mathrm{mg} / \mathrm{kg}$ in Eruca sativa and $4.65 \mathrm{mg} / \mathrm{kg}$ in Petroselinum crispum.

Keywords: acephate pesticide residues, vegetables, TLC, UV/VIS spectrophotometer.
\end{abstract}

(C) RASĀYAN. All rights reserved

\section{INTRODUCTION}

Acephate is an organophosphate insecticide (Chemically known as O,S-dimethyl acetylphosphoramidothioate) shows a residual systemic action (Fig.-1) . It controls insects through contact and stomach action. It effects on the nervous systems of the insects. ${ }^{1,2}$

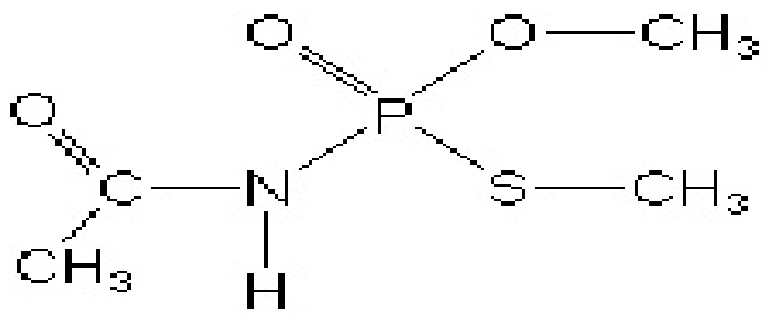

Fig.- 1: Acephate Structure

Acephate insecticide is easily soluble in water soluble and uptaken by the plant which helps in controlling from feeding by insects. Destructive insects are controlled efficiently by ingestion of acephate pesticide. The use of acephate should be frequently as authoritative instruction in order to obtain the best controlling. Acephate is a cholinesterase inhibitor which can be treated with antidotal and 2-PAM and atropine. ${ }^{2,3}$ Acephate was considered to be most effective in reduction in jassid population. It was premium over the rest of the remediation. Acephate is a pesticide applied to control different kinds of insects by feeding or contact. ${ }^{4}$ Acephate was against major insect pests of rice. ${ }^{5}$ It was found to be safe to the sorghum crop if it was applied as recommended dosage. ${ }^{6}$ Acephate minimized $19.56 \%$ dead heart sign. ${ }^{7}$ It was found most active to pest control in the reduction of the population of mustard aphid. ${ }^{8}$

Rasayan J. Chem., 11(3), 979-983(2018)

http://dx.doi.org/10.31788/RJC.2018.1132063

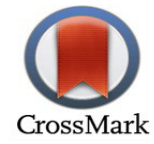


Advancement in pesticides have shared to the upgrade in our living standard, but these development brought with contamination.9, 10 The widely used method for acephate determination depends on chromatographic analysis and identification. Among different chromatographic techniques, LC and GC coupled with various detectors have applied.

But, they required more pretreatment and cleanup processes, before undergoing chromatographic analysis and identification. Mass spectrometry (LC/MS) is used to analyze acephate and methamidophos in trace amount. ${ }^{11}$ HPLC and GC methods have been used for pesticides residues determination at small levels. ${ }^{12}$ Pesticide residues also can determine by LC-ESI-MS/MS in tea sample. ${ }^{13}$ The spectrophotometric method is preferred to the other methods as it is very cheap and simple. ${ }^{14}$ In this work, the pesticide residues of acephate $75 \% \mathrm{SP}$ in some vegetable samples were identified by TLC using the standard solution of acephate, and the content was determined spectrophotometrically.

\section{Samples Area and Preparations}

\section{EXPERIMENTAL}

Vegetable samples were collected from different markets of Baljurashi city, southwest of Saudi Arabia. The samples used in this study were Coriandrum sativum (leaves), Petroselinum crispum and Eruca sativa which are considered to be the commonly used vegetables. The samples were prepared by cutting them into small pieces for each sample separately, and have been dealt with a manner to prevent them from contamination by chemicals or any other pollutants. Each of the samples has been mixed thoroughly homogenous mixture and stored in containers at room temperature for instant analysis.

\section{Chemicals, Reagents, and Apparatus}

An analytical grade of chemicals and deionized water were used in this study. UV-Visible Spectrophotometer (PD-303UV, APEL CO., LT) was also used for spectrophotometric measurements.

\section{Extraction of Pesticide residues in the Vegetable Samples}

About 40 grams of each of the three vegetable samples were weighed separately and transferred to a $500 \mathrm{~mL}$ beaker then $200 \mathrm{~mL}$ of ethyl acetoacetate and $50 \mathrm{ml}$ of deionized water were added. The three mixtures were heated to $75{ }^{\circ} \mathrm{C}$ for 2 minutes and then filtered through Buchner funnel. The filterates of each sample were transferred to a1 liter separatory funnels.

\section{Isolation and Purification of Pesticide Residues}

About $100 \mathrm{ml}$ diethyl ether were added to each of the filtrates of the ethyl acetoacetate extracted samples in the three separatory funnels, shaken for 2 minutes. Then $10 \mathrm{ml}$ of $1 \% \mathrm{NaCl}$ and $600 \mathrm{ml}$ of deionized water were added for each of the separatory funnels and shaken for 1 minute in

a horizontal position. The two layers of organic and aqueous were allowed to form, and then the aqueous layer was removed. The organic layer of each of the samples was washed with deionized water. Each of the three samples organic layers was transferred to the flasks and filtered after addition of $15 \mathrm{~g} \mathrm{of} \mathrm{Na}_{2} \mathrm{SO}_{4}$. After that, the fiterates of each of the three samples were concentrated to a volume of $5 \mathrm{ml}$ for each,and then were subjected to spectrophotometric and chromatographic analysis.

\section{Analysis by Thin Layer Chromatography (TLC)}

TLC is prepared by adding $12 \mathrm{~g}$ of silica gel and $3 \mathrm{~g}$ of hydrated calcium sulphate, mixed well and placed in a beaker, then $30 \mathrm{ml}$ of deionized water were added. The paste is well mixed. The glass was covered with a thin layer, then dried in air for an hour, and activated by placing it in the drying oven at a temperature of $105{ }^{\circ} \mathrm{C}$ and for 30-45 minutes. Concentrated spots of the three sample extracts and the reference pesticide sample (acephate 75\% SP) were put on the TLC plate and then placed in a covered glass tank. The developing system solution was prepared by two methods, one of which was $5 \%$ acetic acid in ethyl acetoacetate, and the other was formic acid, acetic acid, and methanol with the ratio of 1: 5: 1 respectively. The two mobile phases were poured separately for the three samples and a reference sample of the pesticide. The values of the retardation factor $\left(R_{f}\right)$ were calculated for each of the three samples and the reference pesticide in the two developing systems (Tables-1 and 2 ). 


\section{Preparation Standard Solution of Acephate Pesticide}

1. The standard solution of the reference pesticide sample was prepared at a concentration of 1000 ppm by dissolving $1 \mathrm{~g}$ of the pesticide sample in 1 liter of distilled water.

2. Different concentrations of $0.1,0.5,1.0,3.0$ and $5.0 \mathrm{ppm}$ in $100 \mathrm{~mL}$ volume flasks of the standard solution (acephate $75 \% \mathrm{SP}$ ) were prepared.

\section{Determination of Absorption Spectrum}

The absorption spectra of products obtained by the reaction of acephate with anthracene in $\mathrm{HNO}_{3}$. The maximum absorption wavelength peak $\lambda_{\max }$ was found to be $380 \mathrm{~nm}$ against the reagent blank (Fig.-2).

\section{Spectrophotometric Analysis of Acephate Pesticide Residues in Vegetable Samples}

About $2 \mathrm{~mL}$ of each of the prepared solutions of the three vegetable samples were transferred into a test tube, for each $1 \mathrm{ml}$ of anthracene reagent (prepared by dissolving $1 \mathrm{~g}$ of anthracene in $100 \mathrm{ml}$ concentrate $\mathrm{HNO}_{3}$ ) were added for each of the three prepared samples, then add $2 \mathrm{~mL}$ of $\mathrm{NaOH}$ solution $(1.0 \mathrm{M})$ for each, and then wait for 5 minutes until the coloured complex was developed (red/orange). The absorbances of the solutions were measured at $380 \mathrm{~nm}$ for the three prepared samples versus blank (Table-3).

\section{RESULTS AND DISCUSSION}

\section{Thin Layer Chromatography of the Pesticide Residues}

In this work, the pesticide was identified in the three samples by TLC using the standard solution of acephate. Using two mobile phases, one of which was 5\% acetic acid in ethyl acetocyclate and the other is formic acid, acetic and methanol in the ratios of 1: 1: 5. The $\mathrm{R}_{\mathrm{f}}$ values of the reference sample and the three samples were found to be 0.945 and 0.912 respectively for the two developing systems (Tables- 1 and 2).

Table -1: TLC, "Silica gel", 5\% Aqueous Acetic Acid in Ethyl Acetoacetate for Acephate (Standard) and the Extract of Vegetable Samples

\begin{tabular}{c|c}
\hline $\begin{array}{c}\text { Acephate standard and acephate in vegetable } \\
\text { samples }\end{array}$ & $\begin{array}{c}\text { Retardation factor (Rf) in 5\% aqueous acetic } \\
\text { acid in ethyl acetoacetate as developing } \\
\text { system }\end{array}$ \\
\hline Acephate (standard solution) & 0.945 \\
\hline Coriandrum sativum (leaves) & 0.945 \\
\hline Petroselinum crispum & 0.945 \\
\hline Eruca sativa & 0.945 \\
\hline
\end{tabular}

Table -2: TLC, "Silica gel", Formic Acid: Acetic Acid: Methanol 5:1:1 for Acephate (Standard) and the Extract of Vegetable Samples

\begin{tabular}{c|c}
\hline $\begin{array}{c}\text { Acephate standard and acephate in vegetable } \\
\text { samples }\end{array}$ & $\begin{array}{c}\text { Retardation factor (Rf) in formic acid: acetic } \\
\text { acid: methanol 5:1:1 as developing system }\end{array}$ \\
\hline Acephate (standard solution) & 0.912 \\
\hline Coriandrum sativum (leaves) & 0.912 \\
\hline Petroselinum crispum & 0.912 \\
\hline Eruca sativa & 0.912 \\
\hline
\end{tabular}

\section{Absorption Spectra}

The absorption wavelength $\left(\lambda_{\max }\right)$ for the complex of acephate and anthracene in concentrated $\mathrm{HNO}_{3}$ solution (1\% w/v) as chromogenic reagent occurred at $380 \mathrm{~nm}$ against the blank as in (Fig.-2). 


\section{Calibration Curves for the Determination of Acephate}

Calibration curve for the determination of acephate SP 75\% standards with anthracene solution in $\mathrm{HNO}_{3}$ $(1 \% \mathrm{w} / \mathrm{v})$ was constructed by plotting the absorbances as a function of the corresponding concentrations (Fig.-3). The regression equation for the results was $\mathrm{Y}=0.2458 \mathrm{X}+0.0118$ and the $\mathrm{R}^{2}$-value was 0.9993 which indicates the accuracy of the method.

The results showed the presence of pesticide residues in the sample with a concentration of $14.25 \mathrm{mg} / \mathrm{kg}$ in Coriandrum sativum, $4.65 \mathrm{mg} / \mathrm{kg}$ in Petroselinum crispum and $8.10 \mathrm{mg} / \mathrm{kg}$ in Eruca sativa, as shown in Table 3, indicating contamination of selected vegetable samples with the pesticide under study.

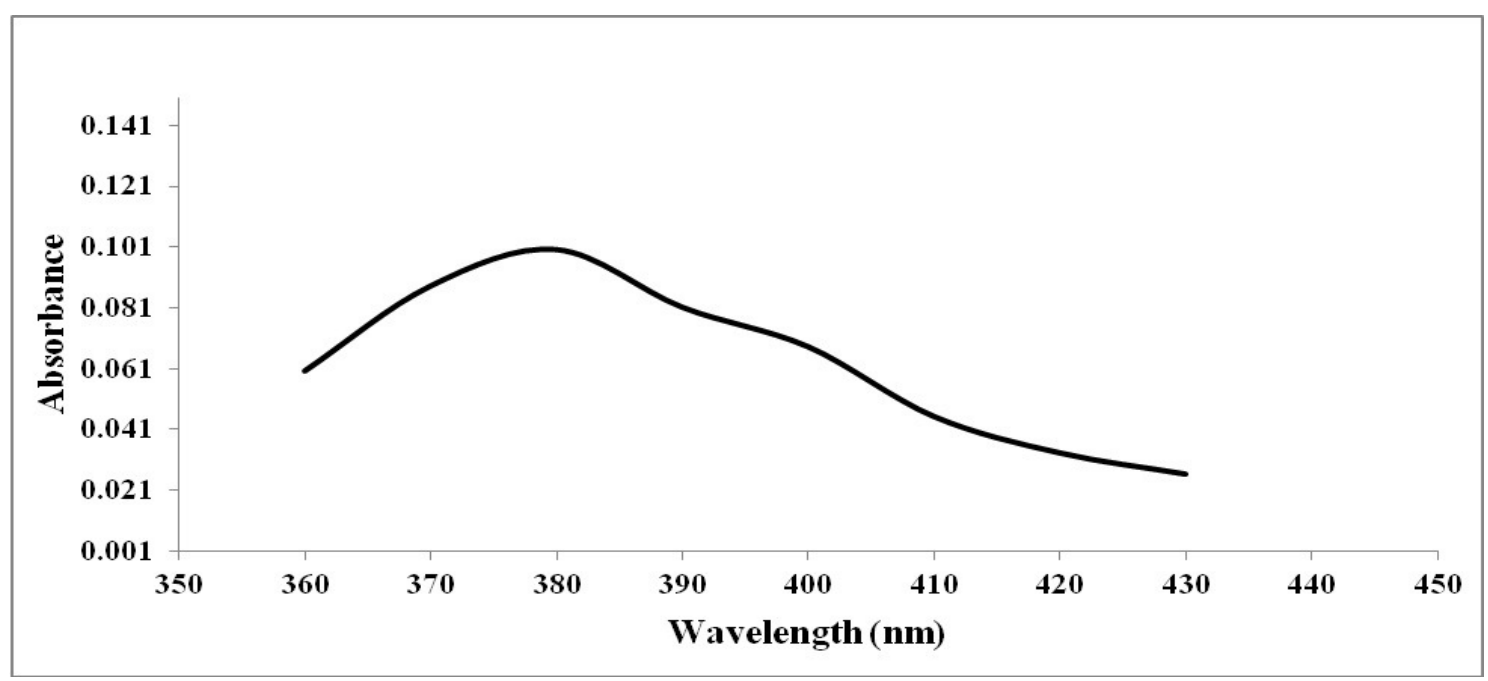

Fig.-2: The Absorption Maxima of the Complex of Acephate $(10 \mu \mathrm{g} / \mathrm{mL})$ and Anthracene Solution (1\% w/v).

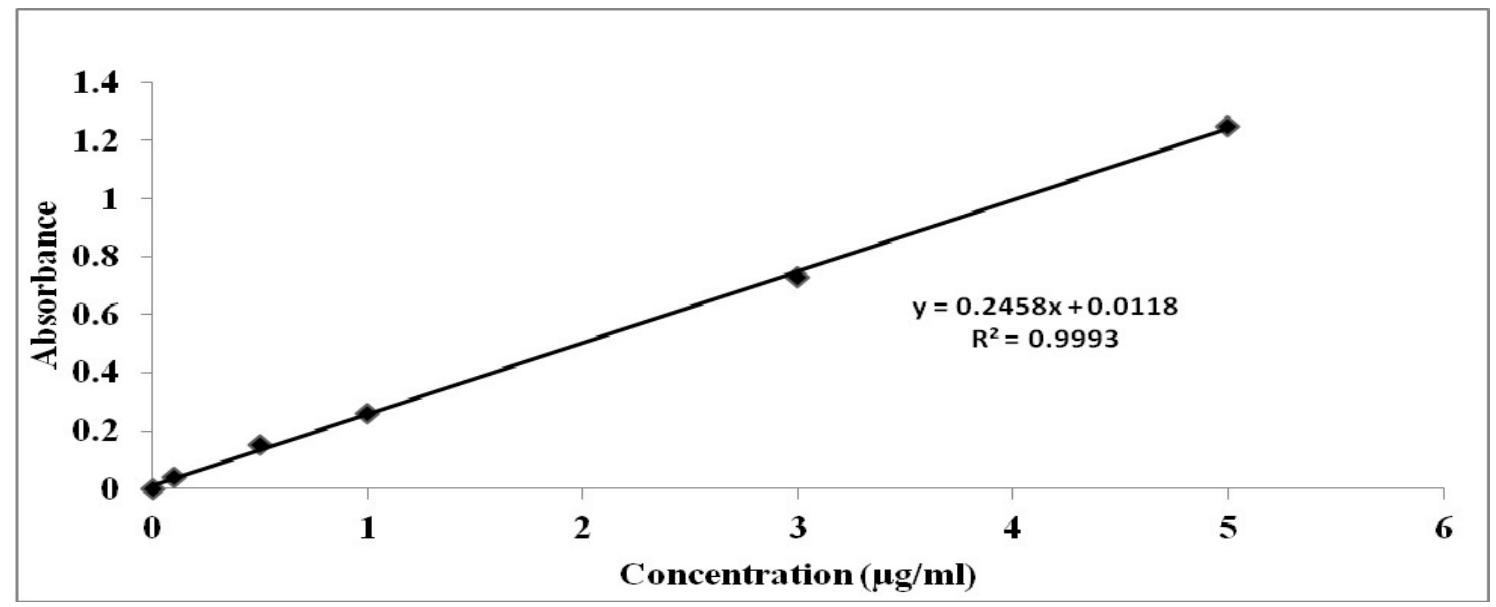

Fig.-3: Calibration Curve for the Determination of Acephate

\section{CONCLUSION}

The study showed simple and fast spectrophotometric determination of pesticide residues of acephate in some vegetables. On another hand, all the chemicals used in this method are cheap and available. This method is important for the quality control of the study pesticide.

Table-3: Amount of Acephate Pesticide Residues in Vegetable Samples by Spectrophotometric Method

\begin{tabular}{c|c|c|c|c|c}
\hline Vegetable samples & $\begin{array}{c}\text { Absorbance } \\
\text { (at } 380 \mathrm{~nm})\end{array}$ & $\begin{array}{c}\text { Acephate } \\
(\mathrm{mg} / \mathrm{L})\end{array}$ & $\begin{array}{c}\text { Acephate } \\
(\mathrm{mg} / \mathrm{L})^{*}\end{array}$ & $\begin{array}{c}\text { Acephate } \\
(\mathrm{mg} / \mathrm{kg})\end{array}$ & $\begin{array}{c}\text { Acephate } \\
\%\end{array}$ \\
\hline Coriandrum sativum & 0.48 & 1.90 & 5.70 & 14.25 & 0.0014 \\
\hline
\end{tabular}


RASĀYAN $J$. Chem.

Vol. 11 | No. 3 | 979 - 983 | July - September | 2018

\begin{tabular}{c|c|c|c|c|c}
\hline (leaves) & & & & & \\
\hline Petroselinum crispum & 0.47 & 1.86 & 1.86 & 4.65 & 0.0005 \\
\hline Eruca sativa & 0.41 & 1.62 & 3.24 & 8.10 & 0.0009 \\
\hline
\end{tabular}

* The corresponding values after multiplication by the dilution factor.

Also, a recommendation could be drawn that pesticides should be used by farmers according to the agricultural extension method recommended by agricultural specialists. Safety factors such as handwashing should be ensured following the use of the pesticide, well ventilation and should keep pesticides out of the reach of children. Thoroughly washing of the vegetables with water in order to get rid of pesticide residues adhered to them and even remove any traces of pesticide residue.

\section{ACKNOWLEDGMENT}

Special thanks to the Chemistry Department, Faculty of Science and Arts at Baljurashi, Albaha University for providing facilities and useful assistance in this study.

\section{REFERENCES}

1. Reregistration Eligibility Decision (RED) Acephate; EPA 738-R-01-013; U.S. Environmental Protection Agency, Office of Prevention, Pesticides and Toxic Substances, Office of Pesticide Programs, U.S. Government Printing Office: Washington, DC,1-87(2006).

2. The United States Environmental Protection Agency, Office of Chemical, Safety and Pollution Prevention, Washington, D.C. 20460 (2011).

3. WHO. Pesticide residues in food - 1976: Acephate; International Programme on Chemical Safety, World Health Organization: Geneva, (1976).

4. R. Sharma, S. Summarwar, International Journal of Fauna and Biological Studies, 4(4), 89 (2017).

5. R. K. Kalyan, D. P. Saini, S. Ramesh Babu, Journal of Entomology and Zoology Studies, 5(3), 1677 (2017).

6. S. Ambarish, A. P. Biradar, S. B. Jagginavar, S. S. Karbhantanal,Journal of Pharmacognosy and Phytochemistry, 6 (5), 1850 (2017).

7. M. S. Islam, S. Das, K. S. Islam, A. Rahman,M.N. Huda, P.K. Dash, International Journal of Biosciences, 3(10), 117 (2013), DOI: 10.12692/ijb/3.10.117-125

8. R. Bhati, R. C. Sharma, A. K. Singh. Biolife, 2(4), 1165 (2014).

9. S. K. Sharmaa, A. Chaudharyb, R.V. Singhc, Rasayan J. Chem., 1(1), 168 (2008).

10. S. K. L. Al-Zurfi, B. M. Ali, A. A. Abojassim, R. A. Albanon, H. A.Qazmooz, Rasayan J. Chem., 9(3), 405 (2016).

11. V. Kumar, N. Upadhyay, V. Kumar, S. Sharma. Arabian Journal of Chemistry, 8, 624 (2015), DOI: 10.1016/j.arabjc.2014.12.007

12. G. H. Tan and M-K. Chai. Sample Preparation in the Analysis of Pesticides Residue in Food by Chromatographic Techniques, Pesticides - Strategies for Pesticides Analysis, InTech Publisher: Rijeka, Croatia, 27- 59 (2011).

13. C. S. Reddy, S. K. Reddy, G. V. S. Reddy, Rasayan J. Chem., 11(2), 582(2018), DOI: 10.7324/RJC.2018.1122077

14. I. E. H. Elgailani, R. H. Alghamdi, Der Pharma Chemica, 9(16), 28(2017).

[RJC-2063/2018] 